\title{
Co-pyrolysis of Waste Biomass with Petroleum Sludge for Improved Energy Recovery
}

\author{
Guangji Hu${ }^{1}$, Jianbing $\mathrm{Li}^{2}$ \\ ${ }^{1}$ University of British Columbia Okanagan Campus, School of Engineering \\ 3333 University Way, Kelowna, British Columbia, Canada V1V 1V7 \\ guangji.hu@ubc.ca \\ ${ }^{2}$ University of Northern British Columbia, Environmental Engineering Program \\ 3333 University Way, Prince George, British Columbia, Canada V2N 4Z9 \\ jianbing.li@unbc.ca
}

\section{Extended Abstract}

The petroleum industry generates a considerable amount of oily sludge during various processes such as crude oil exploration, transportation, storage, and refining. Due to the hazardous nature and increasing production quantity, the effective treatment of oily sludge has become a worldwide pressing need. Traditional methods for oily sludge treatment such as landfilling have been challenged by increasingly stringent regulations because of their low efficiency, long treatment time, and possible secondary pollution. Among various other treatment methods for oily sludge, pyrolysis may represent an effective thermo-chemical conversion process during which the waste is heated in a closed oxygen-free reactor system at moderate operating temperature. The process can convert organic matters into combustible gases, pyrolysis oil, and char. However, many pyrolysis studies have focused on pyrolysis oil production from biomasses because they are considered as abundant and promising renewable energy sources. Although showing a great potential as an alternative energy source, the utilization of bio-oil has been limited due to some drawbacks such as high oxygen and water content, low heating value, and instability. Many previous studies indicated that the co-pyrolysis of biomass with other organic wastes such as waste tires, plastic waste and municipal sewage sludge seems to be a simple and effective way for improving bio-oil quality. Unfortunately, there has been limited research investigating the co-pyrolysis of biomass with refinery oily sludge. As a result, the present study aims to examine the treatment of refinery oily sludge waste using copyrolysis with a wood waste (saw dust) for improved energy recovery. The synergetic effect in co-pyrolysis of sawdust with oily sludge was investigated in a fixed-bed reactor. The impact of three experimental factors including sawdust percentage in the feedstock, temperature, and heating rate on the yield of pyrolysis oils and chars were examined. It was found that the pyrolysis oil yield increased as a result of increasing sawdust percentage and heating rate, and the optimum temperature for oil production was identified as $500{ }^{\circ} \mathrm{C}$. The interaction effect of heating rate and temperature, as well as heating rate and sawdust percentage, were significant on pyrolysis oil yield. The synergetic effect of co-pyrolysis was observed by bringing about $4 \%$ increase in the yield of bio-oil derived from co-pyrolysis as compared to the predicted value, but no obvious effect on char yield was observed. Co-pyrolysis of sawdust with oily sludge at a sawdust percentage higher than $40 \%$ can improve the quality of bio-oil by increasing its $\mathrm{H} / \mathrm{C}$ ratio and higher heating value (HHV). Pyrolysis oil from individual oily sludge treatment had the highest HHV and the lowest moisture. High sawdust percentage in the feedstock also can improve the quality of char product by increasing its carbon content. The results confirmed that using oily sludge as an additive in sawdust pyrolysis could improve pyrolysis oil production, and thus the co-pyrolysis treatment could be a promising way for the disposal of hazardous oily sludge. 